\title{
Correction to: Arts-Based Pathways into Thinking
}

\section{Correction to: \\ M. Crowhurst and M. Emslie, Arts-Based Pathways into Thinking, SpringerBriefs in Arts-Based Educational Research, https://doi.org/10.1007/978-3-030-37507-2}

The original version of the book was inadvertently published with incorrect information. Changes are below.

In Chapter 2, page no. 24, the phrase "delete "cover image_-but Version 2" provided after the text citation "Crowhurst 2009" was removed.

In Chapter 3, page no. 42, “(Joni Mitchell [1975 ]—Shadows and Light)" was aligned to the centre.

In Chapter 4, page no. 48, the unwanted character " $T$ " was removed from the sentence "While a lot of ...".

In Chapter 6, page no. 83, repeated content "His work functions in the same way as a good book leads to writing and a good song leads to playing the guitar ...flow" delete from the poem "Victoria and it resonated ..."

In Chapter 7, page no. 93, "Uther Uther 2011a, b, c" was changed to "Uther 2011a, b, c".

In Chapter 7, page no. 119, a question mark was added to the end of the sentence "Mic: .....between No 1 and No 2". 